Article

\title{
Similarities and Differences in Quorum Sensing-Controlled Bioluminescence between Photobacterium phosphoreum T3 and Vibrio qinghaiensis sp.-Q67
}

\author{
Dan Wang, Linming Bai, Shanshan Li *D and Wei Yan
}

Citation: Wang, D.; Bai, L.; Li, S.; Yan, W. Similarities and Differences in Quorum Sensing-Controlled Bioluminescence between Photobacterium phosphoreum T3 and Vibrio qinghaiensis sp.-Q67. Appl. Sci. 2022, 12, 2066. https://doi.org/ 10.3390/app12042066

Academic Editor: Guillaume Pierre

Received: 17 January 2022

Accepted: 15 February 2022

Published: 16 February 2022

Publisher's Note: MDPI stays neutral with regard to jurisdictional claims in published maps and institutional affiliations.

Copyright: (C) 2022 by the authors. Licensee MDPI, Basel, Switzerland. This article is an open access article distributed under the terms and conditions of the Creative Commons Attribution (CC BY) license (https:// creativecommons.org/licenses/by/ $4.0 /)$.
Xi'an Key Laboratory of Solid Waste Recycling and Resource Recovery, Department of Environmental Science and Engineering, Xi'an Jiaotong University, Xi'an 710049, China; strugglewd531@stu.xjtu.edu.cn (D.W.); bailinming@stu.xjtu.edu.cn (L.B.); yanwei@xjtu.edu.cn (W.Y.)

* Correspondence: shanshan0320@xjtu.edu.cn

\begin{abstract}
Quorum sensing is a density-dependent mechanism using chemical signal molecules termed autoinducers to regulate diverse biological processes in bacteria, including bioluminescence. However, the correlation between growth and light emission of two typical luminescent bacteria, Photobacterium phosphoreum T3 and Vibrio qinghaiensis sp.-Q67, is still unclear. This study investigates the variations of bioluminescence and the light-emission-involved gene expression of the above two strains, respectively, showing that bioluminescence is population density-dependent. Furthermore, the effect of crude extracts $(175,350,700$ and $1750 \mathrm{mg} / \mathrm{L})$ from the bacterial culture that contains the potential autoinducers on the bioluminescence is explored. At the exponential and the early stationary growth phase, T3 did not exhibit an obvious light intensity and cell density change after adding crude extracts at 175 and $350 \mathrm{mg} / \mathrm{L}$, while the light intensity decreased at 700 and $1750 \mathrm{mg} / \mathrm{L}$, showing a luminescence inhibition. For Q67, the light intensity increased dramatically with crude extract concentration. These results suggest that the bioluminescence process of both T3 and Q67 is controlled by quorum sensing. Furthermore, the different response modes of these two strains to autoinducers imply that the two strains could be applied to different compounds for toxicity assesses.
\end{abstract}

Keywords: quorum sensing; quorum sensing; Photobacterium phosphoreum T3; Vibrio qinghaiensis sp.-Q67; bioluminescence; gene expression; toxicity

\section{Introduction}

Quorum sensing (QS) is a microbial cell-cell communication process that depends on the secretion of diffusible chemical molecular-termed autoinducers to regulate associated gene expression in response to cell density [1,2]. When the accumulated autoinducers (in and out of the cell) gradually reach a significant threshold concentration the expression of related genes will be induced, leading to various microbial behaviors, including bioluminescence production and virulence secretion, biofilm formation and so on [3]. Meanwhile, various studies have demonstrated that acyl-homoserine lactone (AHL) is one of the most important autoinducers that mediates the QS-dependent gene expression in Gram-negative bacteria $[4,5]$.

Since QS was first discovered in two marine luminescent bacteria species, Vibrio fischeri (Aliivibrio fischeri) and Vibrio harveyi, over 45 years ago, much effort has been devoted to illustrating the physiological and genetic mechanisms in these two typical microorganisms. One of the well-defined QS systems in V. fischeri is LuxI/LuxR, in which $\operatorname{luxI}$ encodes a protein of 193 amino acids that catalyzes the synthesis of autoinducer N-3oxo-hexanoyl-homoserine lactone (3-oxo- $\mathrm{C}_{6}-\mathrm{HSL}$ ), and LuxR is an intracellular receptor which binds with 3-oxo- $\mathrm{C}_{6}$-HSL to form an initiation complex resulting in the expression of light gene luxICDABE. Later, a second QS system named AinS/AinR was reported in $V$. fischeri. The AinS/AinR functioned like the LuxM/LuxN in V. harveyi, relying on the 
autoinducer N-3-octanoyl-homoserine lactone ( $\left.\mathrm{C}_{8}-\mathrm{HSL}\right)$ [6]. Besides the abovementioned LuxM/LuxN system, there are two other kinds of QS systems in V. harveyi, LuxS/LuxPQ and CqsA/CqsS [7]. These three parallel regulatory systems form multiple feedback loops that regulate the bioluminescence elaborately in $V$. harveyi. The coupling of light-emissioninvolved gene expressions with that of cell population provides the theoretical basis for characterizing quorum sensing by gene expression changes [8]. Alternatively, the diversity of QS systems helps to illustrate QS in the context of bacterial sociality, which has aroused great attention and interest [9].

Currently, the studies on QS systems are always associated with bioluminescence in luminescent bacteria, which is often used in toxicity determination. The marine luminescent bacteria Photobacterium phosphoreum T3 (T3) is a widely used strain to evaluate the biological toxicity of pollutants in different environmental matrices [10]. The freshwater strain Vibrio qinghaiensis sp.-Q67 (Q67) is another testing microbe isolated from the body surface of an edible fish (Cymnocypris przewalskii) in Qinghai Lake, China [11]. Compared with the well-characterized QS systems in $V$. fischeri and $V$. harveyi, few studies have shown firm conclusions about whether the luminescence of T3 and Q67 are controlled by QS systems. Based on protein modeling and function analysis on the Q67 strain, Wang et al. constructed 18 monomer models for functional proteins potentially involved in QS and bioluminescence to explore how the QS system controlled bioluminescence [12]. However, no clear evidence about the mechanism of bioluminescence in the T3 and Q67 strains has been determined experimentally. The study of quorum sensing in the two strains is helpful to explain the relation between bioluminescence and toxicity mechanically. Furthermore, this work will provide a deeper insight into the ecological function of bioluminescent bacteria.

The aim of the project is to investigate the link between bioluminescence and QS systems in the strain T3 and Q67. To this end, physiological and genomic approaches are employed to unravel the relationship among cell density, light intensity and luminescent gene expression. Moreover, the effect of crude extracts from the bacterial culture that contains the potential autoinducers on the light intensity of the two strains was investigated.

\section{Materials and Methods}

\subsection{Bacteria and Culture}

The luminescent bacteria Photobacterium phosphoreum T3 and Vibrio qinghaiensis sp.-Q67 were purchased from China General Microbiological Culture Collection Center (Beijing, China) and Beijing Hamamatsu Corp., Ltd. (Beijing, China), respectively. The T3 strain was cultured in a modified medium according to Jin et al. [13]. Briefly, the culture medium consisted of $3.0 \mathrm{~g} / \mathrm{L}$ glycerine, $5.0 \mathrm{~g} / \mathrm{L}$ yeast extract, $5.0 \mathrm{~g} / \mathrm{L}$ tryptone, $30 \mathrm{~g} / \mathrm{L} \mathrm{NaCl}$ and necessary trace elements in milli-Q water with $\mathrm{pH} 6.8 \pm 0.5$. The Q67 strain was cultured in a medium which included $3.0 \mathrm{~g} / \mathrm{L}$ glycerine, $5.0 \mathrm{~g} / \mathrm{L}$ yeast extract, $5.0 \mathrm{~g} / \mathrm{L}$ tryptone, $4 \mathrm{~g} / \mathrm{L} \mathrm{NaCl}, 3.2 \mathrm{~g} / \mathrm{L} \mathrm{MgCl}_{2}, 2 \mathrm{~g} / \mathrm{L} \mathrm{KBr}, 1 \mathrm{~g} / \mathrm{L} \mathrm{CaSO}_{4}, 4 \mathrm{~g} / \mathrm{L} \mathrm{KCl} \mathrm{pH} 8.5 \pm 0.5$ [14]. The two strains were both cultured at $22 \pm 1{ }^{\circ} \mathrm{C}$.

\subsection{Growth and Bioluminescence Measurements}

Bacterial growth was determined by the optical density at $595 \mathrm{~nm}$ (OD595) using an iMARK ${ }^{\mathrm{TM}}$ Microplate Absorbance Reader (BioRad, Hercules, CA, USA). The light emission intensity (RLU) was measured with the following steps by Modulus ${ }^{\mathrm{TM}}$ Single Tube Multimode Reader (Turner Biosystems, Hercules, CA, USA). The two strains were cultured in solid agars for 3 days at $22 \pm 1{ }^{\circ} \mathrm{C}$, then inoculated into $250 \mathrm{~mL}$ sterilized conical flasks containing $80 \mathrm{~mL}$ of liquid medium. After incubation for $12 \mathrm{~h}\left(22 \pm 1^{\circ} \mathrm{C}\right.$, $150 \mathrm{rpm})$, the OD595 and luminescent intensity of T3 strain reached $0.85 \pm 0.05$ and $6.5 \times 10^{7} \pm 10^{4}$ RLU, respectively; the OD595 and luminescent intensity of Q67 reached $1.25 \pm 0.05$ and $2.7 \times 10^{6} \pm 10^{3}$ RLU, respectively. Before each light emission intensity test, $100 \mu \mathrm{L}$ bacterial suspension and $900 \mu \mathrm{L}$ diluent ( $3 \% \mathrm{NaCl}$ for $\mathrm{T} 3$ and $0.4 \% \mathrm{NaCl}$ for Q67) were added into a $1.5 \mathrm{~mL}$ EP tube. Every test was performed in triplicate. 


\subsection{Quantification of Relative Expression Levels of the Selected Luminant Gene}

According to the growth curves of the two strains, six diverse bacterial cultures were sampled at different times. The total RNA of each sample was isolated using the RNAprep pure Cell/Bacterial kit (Tiangen Biotech, Beijing, China). The RNA was quantified at Qubit $^{\mathrm{TM}} 4.0$ Fluorometer (Thermo Fisher Scientific, Singapore) and then used to synthesize cDNA with Evo M-MLV RT Kit (Accurate Biology, Changsha, China) according to the manufacturer's instruction. Subsequently, real-time polymerase chain reaction (RT-PCR) was performed with the produced cDNA as the template using SYBR Green premix (Accurate Biology, Changsha, China). All reactions were carried out in triplicate using a LightCycler 96 instrument (Roche, Basel, Switzerland). The $2^{-\Delta \mathrm{Ct}}$ method was used to figure out the relative expression levels of the selected genes with Equations (1) and (2). The primer sequences used in this study are listed in Tables S1 and S2.

$$
\begin{gathered}
\Delta \mathrm{Ct}_{(\mathrm{Si}, \mathrm{x})}=\mathrm{Ct}_{(\mathrm{Si}, \mathrm{x})}-\mathrm{Ct}_{(\mathrm{Si}, 16 \mathrm{~S} \text { rRNA })} \\
\mathrm{R}=2^{-\left(\Delta \mathrm{Ct}_{(\mathrm{Si}, \mathrm{x})}\right)}
\end{gathered}
$$

where the expression levels of the selected genes are relative to the endogenous gene (16S rRNA), Ct is the cycle time, $\mathrm{Si}$ is the ith sampling time referring to $\mathrm{S} 1$ to $\mathrm{S6}$, $\mathrm{x}$ represents the selected gene in this experiment and $\mathrm{R}$ is the relative expression ratio.

\subsection{Preparation of Crude Extract from Cell-Free Supernatants}

T3 and Q67 cells were cultivated in $170 \mathrm{~mL}$ liquid medium at $25{ }^{\circ} \mathrm{C}$ with shaking at $150 \mathrm{rpm}$ to stationary phase, respectively. After centrifugation at $8000 \mathrm{rpm}$ for $10 \mathrm{~min}$, the supernatant was filtered using $0.22-\mu \mathrm{m}$ membrane filters and extracted twice with an equal volume of ethyl acetate. The organic phase was collected and evaporated by a rotary evaporator (Shenye, Shanghai, China) and the final extracts $(0.06 \mathrm{~g})$ as crude extracts were stocked at $-20{ }^{\circ} \mathrm{C}$ for further use.

\subsection{Influence of Crude Extract on Bacterial Luminescence}

The 1\% $(v / v)$ of overnight cultured T3 and Q67 cells were inoculated into $20 \mathrm{~mL}$ liquid mediums, respectively. Then, a series of the stocked crude extracts with different concentrations were added to the two bacterial mediums. The inoculated medium without crude extract was used as a control. To compare the growth ability of crude extract affected by the T3 and Q67, the time-dependent effect of crude extract on growth and bioluminescence was measured, respectively. Each experiment was performed in triplicate.

\subsection{Statistical Analysis}

The data were analyzed with Graph Prism and presented as mean \pm standard deviation. Difference between the control and test groups were analyzed by Student's $t$-test. $p$ values less than 0.05 were considered statistically significant.

\section{Results and Discussion}

\subsection{The Genes Associated with Luminescence in P. phosphoreum and V. qinghaiensis}

As for QS-controlled luminescent bacteria, the regulatory elements in gene cluster are essential for light production. Therefore, we represented the arrangement of bacterial luminescence genes, including the gene upstream of the core light genes (lux CDABEG) in $V$. fischeri, P. phosphoreum and V. qinghaiensis (Figure 1). The core light genes (luxCDABEG) are involved in all three strains. The $\operatorname{lux} \mathrm{A}$ and $\operatorname{lu} x \mathrm{~B}$ encoded two subunits of luciferase, constituting the basis of bacterial luciferase; the $\operatorname{lu} x \mathrm{C}, \operatorname{lu} x \mathrm{D}, \operatorname{lu} x \mathrm{E}$ were responsible for the conversion process of long-chain fatty acids to fatty aldehydes, encoding the fatty acid reductase, transferase and synthase, respectively [15]. The functional lux $\mathrm{G}$ is considered the source of reduced flavins for a catalytic process [16]. 


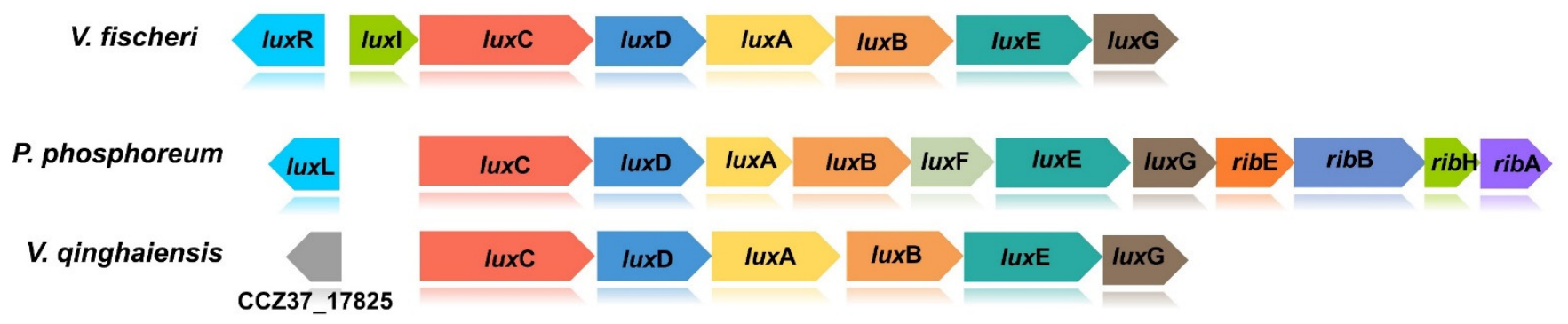

Figure 1. The arrangement of bacterial luminescence $(l u x)$ genes in three bacteria. Comparison of the size and order of lux genes in three bacteria using diverse colour arrangements to highlight commonalities and differences.

Compared to the luminescence (lux) genes among the three strains, one significant difference is the genes upstream of the core light genes (luxCDABEG) (Figure 1). The upstream gene in the opposite direction of Vibrio fischeri is luxR, which forms the lux $\mathrm{I} /$ lux $\mathrm{R}$ regulatory system with $\operatorname{luxI}$ (Table 1). The LuxI/LuxR system mainly regulates the lux operon (luxCDABEG) expression, which contains the genes necessary for light production in $V$. fischeri. Compared with $V$. fischeri, the regulatory mechanisms of bioluminescence are not well clarified in P. phosphoreum and V. qinghaiensis. Instead of $l u x \mathrm{I}$ and $l u x \mathrm{R}, l u x \mathrm{~L}$ (also named lumP in P. leiognathi, Table 1) is located upstream of the lux operon and transcribed in the opposite direction in P. phosphoreum. It has been found that lumazine protein encoded by $l u x \mathrm{~L}$ plays a role in light emission processes involved in wavelength and intensity transformation. Its derivatives are direct precursors of riboflavin [17]. Compared with the luminant operon of $V$. fischeri, $V$. qinghaiensis sp.-Q67 possessed a gene named CCZ37-17825 located in the opposite direction upstream of $\operatorname{luxC}$, whose function is still unknown [18]. Furthermore, Photobacterium possesses lux $\mathrm{F}$ and rib genes absent from the lux operon of Vibrio species. It is believed that $l u x \mathrm{~F}$ encoded non-fluorescent flavin proteins which could bind with the bioluminescence inhibitor myristylated FMN to increase the luminescent intensity indirectly [19]. That may be one reason why P. phosphoreum is the brightest species among all the reported bioluminescent bacteria [20]. The additional rib genes (ribEBHA) are related to the redox process of $\mathrm{FMNH}_{2}$, involved in the transformation and synthesis of riboflavin. Few studies have reported the presence of QS-associated genes in P. phosphoreum, and the relationship between bioluminescence and QS has not been clear in this species until now. Compared with V. fischeri, the luxI gene is missing in strain Q67, which is generally recognized as a crucial gene to encode the autoinducer synthase in $V$. fischeri.

Table 1. Comparison of the gene associated with luminescence in three species.

\begin{tabular}{|c|c|c|c|c|c|}
\hline Bacterium & $\begin{array}{l}\text { Gene Upstream the } \\
\text { lux CDAB(F)EG Operon }\end{array}$ & $\begin{array}{l}\text { Location } \\
\text { in Genomes }\end{array}$ & $\begin{array}{c}\text { NCBI } \\
\text { Accession Number }\end{array}$ & Fragment Size (nt) & $\begin{array}{l}\text { EncoProtein } \\
\text { Length (aa) }\end{array}$ \\
\hline V. fischeri & $\operatorname{lux} \mathrm{I}$ & 1048783-1049355 & HQ436485 & 573 & 190 \\
\hline P. phosphoreum & $\operatorname{lux} \mathrm{R}$ & 1049571-1050323 & L21989 & 753 & 250 \\
\hline V. qinghaiensis & $\operatorname{lux} \mathrm{L}$ & $1127275-1127847$ & $\begin{array}{c}\text { CP022742 REGION: } \\
900787.901089\end{array}$ & 573 & 478 \\
\hline
\end{tabular}

Based on the above description, the present luminant regulatory genes in P. phosphoreum and $V$. qinghaiensis differed from that in $V$. fischeri on both arrangement and nucleotide acid sequences. These differences among the genes associated with the bioluminescence might indicate the presence of different QS systems other than the typical LuxI/LuxR in those two luminescent bacteria. Thus, the following experiments investigated the relationship between bioluminescence and lux gene expression in P. phosphoreum and V. qinghaiensis.

\subsection{Similarities in Cell-Density-Dependent Control of Bioluminescence between T3 and Q67}

The P. phosphoreum T3 and V. qinghaiensis sp.-Q67 were cultured to measure the growth and luminescence over time, respectively (Figure $2 a, b$ ). The growth and luminescence 
curves of the two strains had obvious lag time. After cultivation of T3 and Q67 for about $3 \mathrm{~h}$ and $4 \mathrm{~h}$, respectively, the growth of both strains entered the exponential phase, and the luminescence began to increase accordingly. Compared with Q67, the luminescent curve of T3 showed the maximum luminescence intensity increased by two orders of magnitude, reaching 1010. Based on Figure $2 a, b$, the variation of emitted light intensity (RLU) with cell density (OD) was plotted in Figure $2 c, d$, respectively. The OD-RLU diagrams of the two strains showed similar variation patterns. The RLU decreased with OD until the OD reached a specific value of 0.10 and 0.46 in T3 and Q67, respectively. After the OD increased above a specific value, the RLU increased. The luminescence intensity reached a fixed order of magnitude when the OD of T3 reached 0.52, and that of Q67 was 1.08. The results indicated that the bioluminescence of both strains is associated with thresholds, below which light would not be emitted. Furthermore, this variation pattern of the OD-RLU curves of both T3 and Q67 is consistent with that of $V$. fischeri, in which the bioluminescence was controlled by QS systems. Thus, the above results suggested that bioluminescence may be controlled by QS in both strains, as in V. fischeri [21].

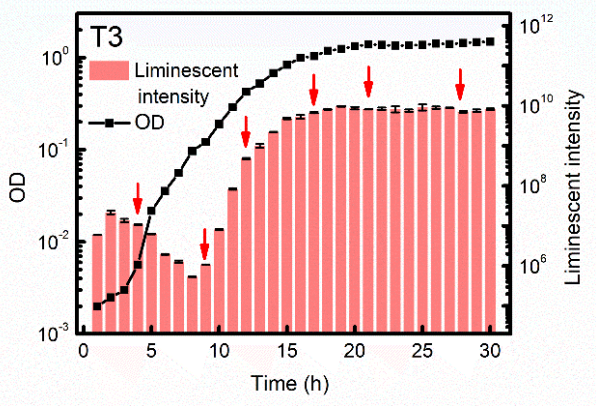

(a)

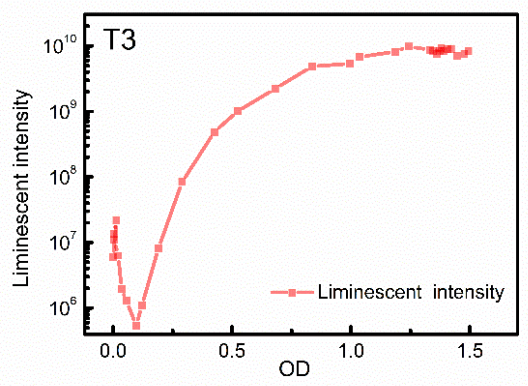

(c)

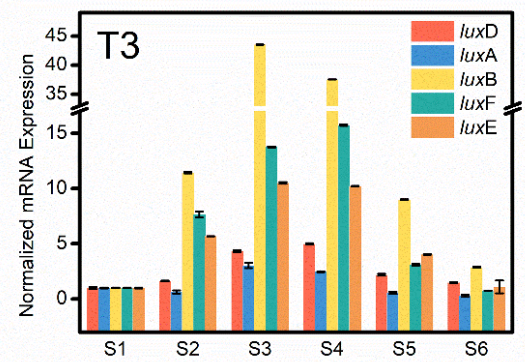

(e)

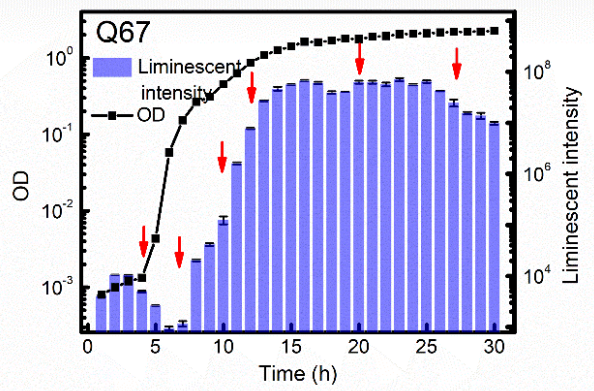

(b)

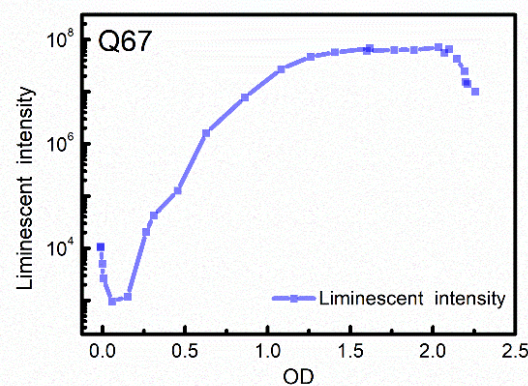

(d)

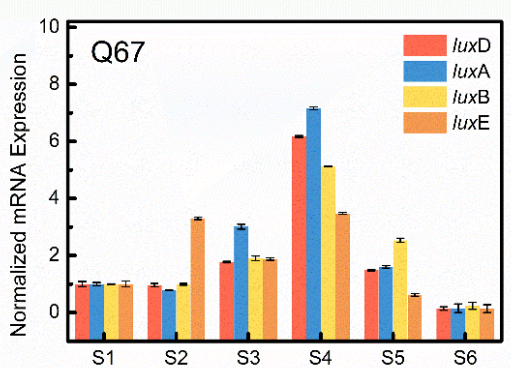

(f)

Figure 2. Bioluminescence and lux gene-expression levels of T3 and Q67 throughout the growth phases. (a,b) Growth and bioluminescence kinetics of T3 and Q67. Red arrows represent the sampling times S1 to S6. (c,d) Light emission of T3 and Q67 according to cell density. (e,f) Expression level of the $l u x \mathrm{DAB}(\mathrm{F}) \mathrm{E}$ genes in T3 and Q67 for sampling times S1-S6. 
To further demonstrate the luminescence behaviour, the luminescent gene expression level on diverse growth phases of T3 and Q67 was monitored by RT-PCR (Figure 2e,f). As for strain $\mathrm{T} 3$, the expression level of selected $l u x$ gene, including $l u x \mathrm{~B}, l u x \mathrm{~F}, l u x \mathrm{E}, l u x \mathrm{D}$ and $\operatorname{lu} x \mathrm{~A}$, in the exponential growth phase (S2, S3 and S4) was much higher than that in the lag and stationary phase (S1, S5 and S6). The luxB encoding beta subunit of luciferase exhibited a significant variation range in the expression level of T3, which dramatically raised by 44-fold in S3 than that in S1. One of the potential explanations for this result was that luciferase-encoding gene $l u x \mathrm{~B}$ played a crucial role in the bioluminescence of $\mathrm{T} 3$, causing the higher luminescence intensity of T3 $\left(10^{3}-10^{4}\right.$ fold) than that of Q67 at the same cell density (Figure 2a,b). Besides that, it is worth mentioning that $l u x \mathrm{~F}$, which was considered to originate from the ancestral $l u x \mathrm{~B}$ gene in Photobacterium, also showed a higher relative expression level, with its role as a scavenger for myrFMN to inhibit luciferase [22,23].

The variation pattern of $l u x$ expression in Q67 was different from that in T3. The maximum increases were observed in S4. Among them, the relative expression of $\operatorname{luxA}$ exhibited the maximum variation and increased seven-fold in $\mathrm{S} 4$, followed by $l u x \mathrm{D}$ with a six-fold increase. For the $l u x \mathrm{~B}$ gene, its expression level was relatively low and the maximum expression level in S4 increased by five-fold, which differs from strain T3 in that lux $\mathrm{B}$ dramatically rose in the exponential phase. Some studies demonstrated that in Vibrio, the key active site for luminescence is in the alpha-subunit of luciferase (luxA), while the beta-subunit, which is encoded by $\operatorname{lu} x \mathrm{~B}$, is presumably responsible for the conformation stability. Visick and Ruby reported that a non-luminous strain of $V$. fischeri could produce light using electroporation in combination with gene replacement, which suggested a sufficient role of luxA for light production in $V$. fischeri. Thus, it was hypothesized that $\operatorname{luxA}$ plays a crucial role in the luciferase expression of Q67, which also belongs to Vibrio [24].

From the study on the variations of bioluminescence and the light-emission-involved gene expression of the T3 and Q67, the results showed that the bioluminescence of the two strains was population density-dependent. It is evident that the two bacteria are quorum-sensing controlled.

\subsection{Differences in the Stimulations of Crude Culture Extract between T3 and Q67}

QS as a cell-density-dependent phenomenon allowed bacteria to coordinate their physiology via the release of autoinducers (AIs). Once AIs were produced by the corresponding synthases, they were sent out and perceived by the community microbes that enumerate their population density. After reaching threshold concentrations, changes in microbial gene expression are induced, triggering population cooperation. The primary AIs synthesized by gram-negative bacteria are AHL molecules that consist of a homoserine lactone ring (HSL) with an acyl chain. The acyl-chain length generally varies from C4 to C18 and can be modified by a 3-oxo substituent, a 3-hydroxy substituent, a terminal methyl branch, or varying degrees of unsaturation. In wastewater treatment, studies have borne out claims that exogenous addition of AHLs or AHL-producing bacteria could enhance sludge performance, such as biofilm and maturation [25], microbial aggregation and stabilization [26] and granule formation [27]. According to the report of Lv et al. [26], exogenous AHLs (3-oxo- $\mathrm{C}_{8}-\mathrm{HSL}, \mathrm{C}_{8}$-HSL, $\mathrm{C}_{6}$-HSL and $\mathrm{C}_{4}$-HSL) enhanced the degrading ability of oligotrophic anaerobic granular sludge to remove residual refractory substances and optimize the microbial community structure by increasing the abundances of favourable bacterial groups. Concerning luminescent bacteria, the luminescent intensity would increase with the autoinducers in a certain concentration range. A case reported by Perez and Hagen supported the statement that the luminescence intensity of $V$. fischeri would increase when the amount of adding autoinducer was 10 to $100 \mathrm{nM}$ [28]. Smith and Salisbury also found that the bioluminescence of $V$. fischeri in bacterial cultures with AHLs (3-oxo-C6-HSL, $1 \mu \mathrm{M}$ ) commenced earlier and was approximately $100 \%$ greater after $8.5 \mathrm{~h}$ compared with the untreated controls [29]. Therefore, the crude culture extracts containing potential AIs from the two bacterial supernatants were prepared and introduced into the culture media at 
different concentrations ( $175 \mathrm{mg} / \mathrm{L}, 350 \mathrm{mg} / \mathrm{L}, 700 \mathrm{mg} / \mathrm{L}$ and $1750 \mathrm{mg} / \mathrm{L}$ ) to investigate the effect of potential AIs on the growth and the light intensity of the T3 and Q67 (Figure 3).

a

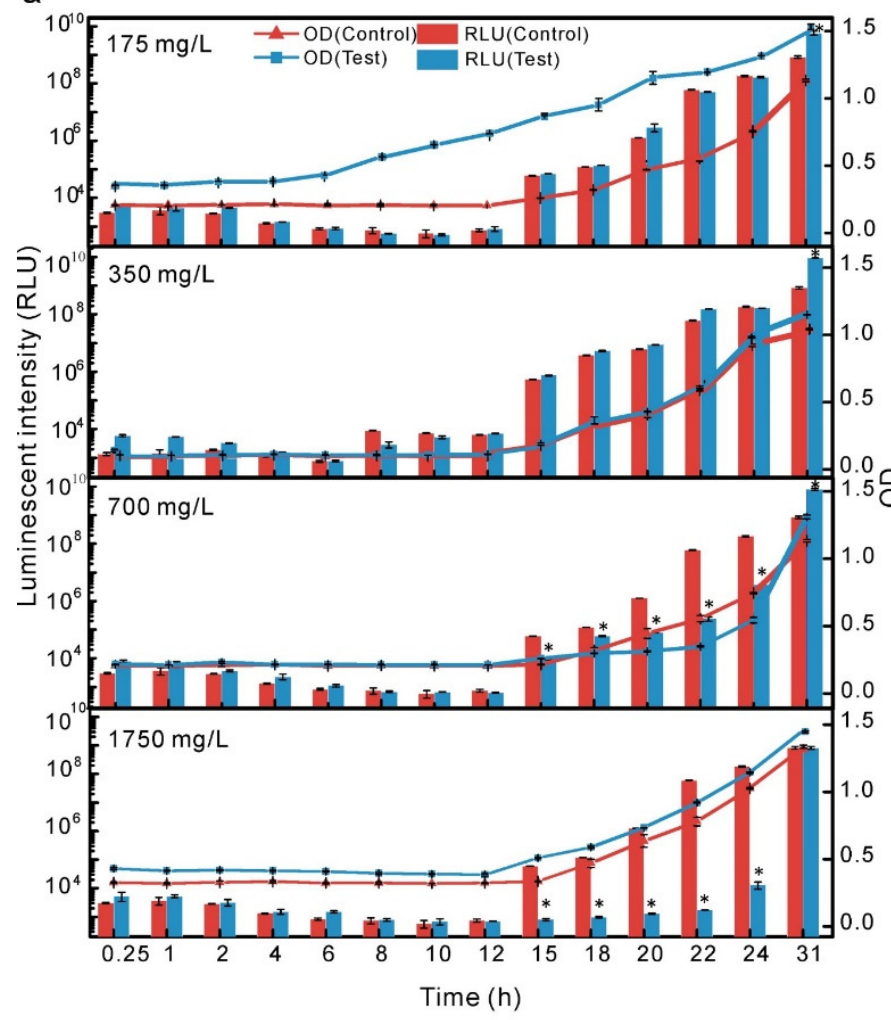

$\mathrm{b}$

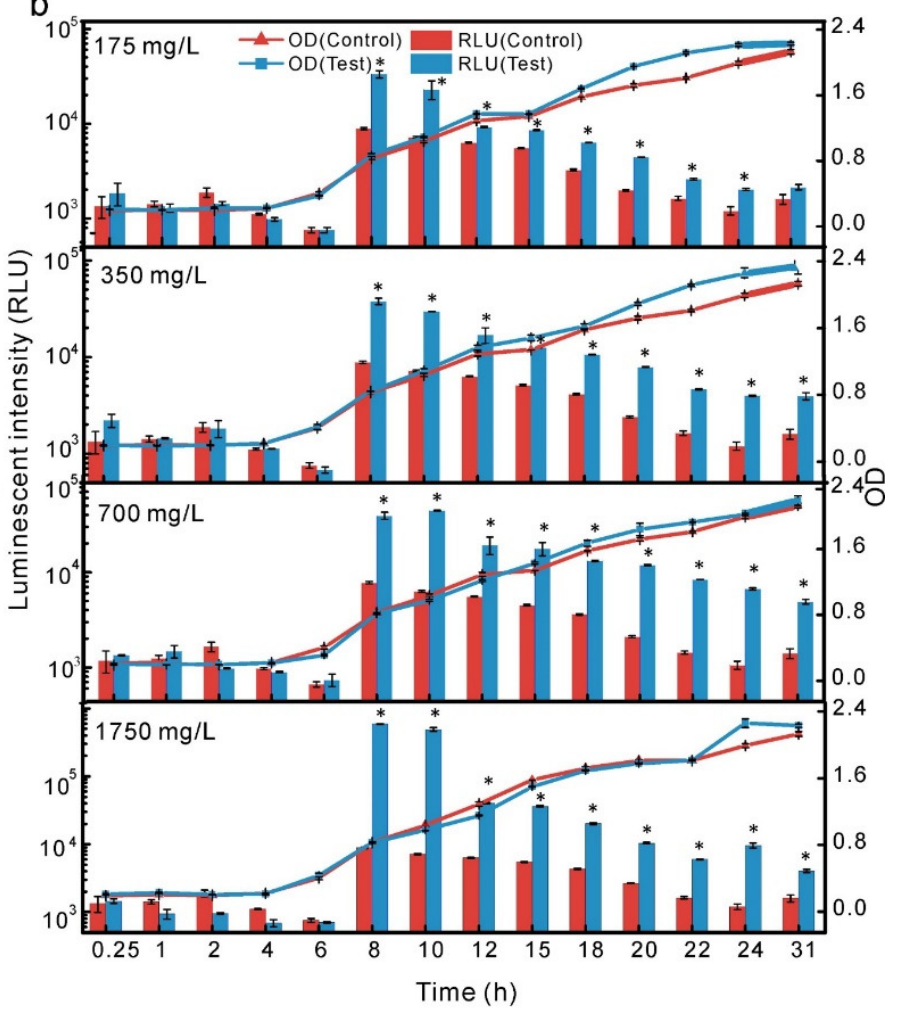

Figure 3. The variation of growth and luminescence level following the addition of crude extract at different concentrations in T3 (a) and Q67 (b). * represents $p<0.05$.

For Q67, the stimulus effects of the crude extract were not noteworthy in test groups during $0.25-8 \mathrm{~h}$ (Figure $3 \mathrm{~b}$ ). However, the light intensity dramatically increased in all test groups after $8 \mathrm{~h}$ compared with control groups (without crude culture extract addition). Furthermore, the luminescence intensity was enhanced with the increasing concentration of added crude extract after $8 \mathrm{~h}$. It is worth mentioning that there were no significant differences in cell density between the control and the test group throughout the experiment. When the added crude extract was up to $1750 \mathrm{mg} / \mathrm{L}$, the cell density (OD) of the control and test group at $8 \mathrm{~h}$ reached 0.80 , while the luminescence intensity of the test group increased by 100 -fold (Figure $3 \mathrm{~b}$ ). This result indicated that the potential autoinducers in crude extract could work with the receptor protein to turn on the expression of the light-emitting gene for Q67.

The test groups of $\mathrm{T} 3$ did not show an obvious light intensity and cell density change after adding extra crude extracts with lower concentrations of 175 and $350 \mathrm{mg} / \mathrm{L}$ (Figure 3a). When adding the crude extracts at 700 and $1750 \mathrm{mg} / \mathrm{L}$, the light intensity decreased with the increase of extract dosage at the exponential and the early stationary growth phase. After adding up to $1750 \mathrm{mg} / \mathrm{L}$, the luminescence intensity of the control group and the test group were $5.6 \times 10^{7}$ and $1.7 \times 10^{3}$ respectively, and the luminescence inhibition rate of the test group was up to $99.99 \%$ at $22 \mathrm{~h}$. Intriguingly, the light intensity of the test group was almost identical to that of the control group at $31 \mathrm{~h}$. In terms of OD, there was no significant difference between the test and the control groups at different addition concentrations. As the OD increases, the excess AIs are perceived by the increased bacteria population and synchronize the expression of $l u x$ genes, actively promoting light production. In accordance with the present results, the luminescent inhibition of the excess autoinducers was revealed by Schaefer et al. [30]. Studies have shown that autoinducer analogues have 
competitive effects due to their different affinity for sites, which leads to bioluminescence inhibition. It has been found that a high concentration of either C8-HSL or 3-oxo-C6-HSL will inhibit light production of $V$. fischeri [31]. The importance of the amount of AHLs also has been demonstrated in other AHLs-mediated processes [32-34]. For example, Wang et al. studied the response of 12 AHLs with different concentrations to biomass adhesion of Sphingomonas rubra biofilms. They found the threshold of AHLs concentration for biofilm formation ranged from $10 \mathrm{ng} / \mathrm{L}$ to $10 \mu \mathrm{g} / \mathrm{L}$. Among them, the response concentration of the biofilm cultured with bulking sludge to most $\mathrm{AHLs}\left(\mathrm{C}_{12}-\mathrm{HSL}, \mathrm{C}_{6}-\mathrm{HSL}, 3-\mathrm{oxo}-\mathrm{C}_{14}-\mathrm{HSL}\right)$ was $10 \mathrm{ng} / \mathrm{L}$ [35]. This result indicated exogenous AHLs might be useful in improving the settling property of bulking sludge. However, adding high-concentration AHLs may interfere with the response of the bacterial community to environmental changes, resulting in the inhibition of biofilm formation. Based on the above discussion, we speculated that the higher doses ( $>1$ fold) of autoinducers in crude extract might repress light production of T3 strain during the mid-exponential and early stationary phases.

The two bacteria showed different responses when exposed to crude extract containing autoinducers. The T3 strain did not exhibit an obvious light intensity and cell density change after adding crude extracts at low concentrations (175 and $350 \mathrm{mg} / \mathrm{L})$, while the light intensity decreased at high concentrations. The light intensity of Q67 strain increased dramatically with crude extract concentration. The two different performances of T3 and Q67 have important implications for toxicology.

\subsection{Toxicological Significance}

The luminescent bacteria have been frequently employed for the ecotoxicological screening and assessment of a wide range of potentially deleterious solid, liquid and gaseous substances. The field of toxicity assessment has used the traditional threshold models, linear-no-threshold (LNT) models and hormesis models for study on dose response [36]. Besides the threshold and LNT models, some scholars have proposed the hormesis model to the toxicological evaluation system with an in-depth understanding of hormesis. Hormesis describes a dose-effect relationship characterized by low-dose stimulation and high-dose inhibition. The hormetic effects of heavy metals [37], sulfonamides [38] and ionic liquids [39] on luminescent bacteria have been reported.

Meanwhile, a few studies have suggested that different species of luminescent bacteria exposed to the same chemical would cause different bioluminescent responses. For example, 1-ethyl-3-methyl imidazolium tetrafluoroborate $(0.01-0.1 \mathrm{~mol} / \mathrm{L})$ has a hermetic response to the luminescence of Q67 in the long-term (12 h) toxicity assessment, while a classic concentration response has been observed for $V$. fischeri, other than the hormesis at the same experimental concentration [40]. These results are closely related to the differences in the luminescent regulatory systems of various luminescent bacteria. Therefore, some researchers introduced quorum sensing to toxicity assessment to explain the different luminescence phenomena of luminescent bacteria in response to the same chemical. Based on the molecular docking and quantitative structure-activity relationships, Deng et al. proposed a new hormesis hypothesis for the chronic toxicity evaluation of sulfonamides (SAs) on P. phosphoreum which combined QS with hormesis to explain the dose-dependent and time-dependent characteristics of hormesis [41]. The hypothesis stated that at a low SAs exposure, the SAs have the chance to bind to a receptor protein (LuxR) and might cause the accumulation of LuxR-SA complexes. The autoinducers increase with the cell density and the accumulated autoinducers bind to LuxR, causing bioluminescence. The LuxR-SA complexes might help the bacteria at low density to activate quorum sensing, exhibiting hormesis. At a high SAs exposure, more SAs might bind to dihydropteroate synthase and inhibit folate synthesis, and toxicity was observed when inhibition exceeded stimulation.

Of particular note, most reports have illustrated the mechanism of the hormesis effect in $V$. fischeri on the molecular level since the QS regulation of $V$. fischeri has been studied in detail. As in previous studies, the toxicity mechanism on P. phosphoreum T3 and $V$. qinghaiensis sp.-Q67 is still unclear on account of lacking conclusions about whether 
the luminescence process of these two strains is controlled by QS systems. The results of our study showed that the bioluminescence production of T3 and Q67 was controlled by QS, which provided a research basis to reveal the relationship between hormesis and QS in toxicology. Moreover, the crude extract containing autoinducers may trigger different responses to $P$. phosphoreum T3 and V. qinghaiensis sp.-Q67, implying that luminescent bacteria with different luminescent properties could be applied to various compounds for toxicity assessment.

\section{Conclusions}

Through physiological and genetic approaches, our study indicated that the luminescence of Photobacterium phosphoreum T3 and Vibrio qinghaiensis sp.-Q67 are both controlled by QS mechanisms. Furthermore, the luminescence intensity varied with the amount of crude extract, and it is speculated that the potential autoinducers in the crude extract could influence the bioluminescence intensity of both strains. The result of the different response modes of these two strains to autoinducers implied the two strains could be applied to the specific identification of pollutants with different toxic modes of action.

Supplementary Materials: The following supporting information can be downloaded at: https:

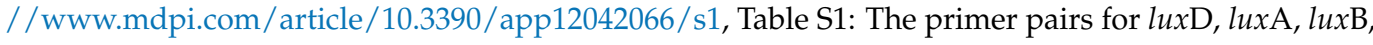
luxF, luxE and 16S rRNA in Photobacterium phosphoreum T3; Table S2: The primer pairs for lux D, luxA, lux $\mathrm{B}, \operatorname{lu} x \mathrm{E}$ and 16S rRNA in Vibrio qinghaiensis sp.-Q67.

Author Contributions: Conceptualization, all authors; methodology, D.W. and L.B.; validation, S.L.; investigation, D.W. and L.B.; writing—original draft preparation, D.W.; writing—review and editing, all authors; supervision, S.L. and W.Y.; project administration, W.Y.; funding acquisition, S.L. All authors have read and agreed to the published version of the manuscript.

Funding: This research was funded by National Natural Science Foundation of China (No. 31670512).

Institutional Review Board Statement: Not applicable for studies not involving humans or animals.

Informed Consent Statement: Informed consent was obtained from all subjects involved in the study.

Data Availability Statement: All data for this work are provided in the text.

Conflicts of Interest: The authors declare no conflict of interest.

\section{References}

1. Mukherjee, S.; Bassler, B.L. Bacterial quorum sensing in complex and dynamically changing environments. Nat. Rev. Microbiol. 2019, 17, 371-382. [CrossRef] [PubMed]

2. Jiang, Q.; Chen, J.; Yang, C.; Yin, Y.; Yao, K. Quorum Sensing: A Prospective Therapeutic Target for Bacterial Diseases. Biomed Res. Int. 2019, 2019, 2015978. [CrossRef] [PubMed]

3. Whiteley, M.; Diggle, S.P.; Greenberg, E.P. Progress in and promise of bacterial quorum sensing research. Nature 2017, 551, 313-320. [CrossRef] [PubMed]

4. Papenfort, K.; Bassler, B.L. Quorum sensing signal-response systems in Gram-negative bacteria. Nat. Rev. Microbiol. 2016, 14, 576-588. [CrossRef]

5. Breijyeh, Z.; Jubeh, B.; Karaman, R. Resistance of Gram-Negative Bacteria to Current Antibacterial Agents and Approaches to Resolve It. Molecules 2020, 25, 1340. [CrossRef]

6. Kimbrough, J.H.; Stabb, E.V. Comparative analysis reveals regulatory motifs at the ainS/ainR pheromone-signaling locus of Vibrio fischeri. Sci. Rep. 2017, 7, 11734. [CrossRef]

7. Watve, S.; Barrasso, K.; Jung, S.A.; Davis, K.J.; Hawver, L.A.; Khataokar, A.; Palaganas, R.G.; Neiditch, M.B.; Perez, L.J.; Ng, W.L. Parallel quorum-sensing system in Vibrio cholerae prevents signal interference inside the host. PLoS Pathog. 2020, 16, e1008313. [CrossRef]

8. Miller, M.B.; Bassler, B.L. Quorum sensing in bacteria. Annu. Rev. Microbiol. 2001, 55, 165-199. [CrossRef]

9. Abisado, R.G.; Benomar, S.; Klaus, J.R.; Dandekar, A.A.; Chandler, J.R. Bacterial Quorum Sensing and Microbial Community Interactions. mBio 2018, 9, e02331-17. [CrossRef]

10. Wang, D.; Wang, S.; Bai, L.; Nasir, M.S.; Li, S.; Yan, W. Mathematical Modeling Approaches for Assessing the Joint Toxicity of Chemical Mixtures Based on Luminescent Bacteria: A Systematic Review. Front. Microbiol. 2020, 11, 1651. [CrossRef]

11. Zhu, W.J.; Wang, J.; Chen, X.Y.; Zhaxi, C.R.; Yang, Y.; Song, Y. A new species of luminous bacteria Vibrio qinghaiensis sp. Oceanol. Limnol. Sin. 1994, 25, 273-279. (In Chinese) 
12. Wang, Z.J.; Chen, F.; Xu, Y.Q.; Huang, P.; Liu, S.S. Protein Model and Function Analysis in Quorum-Sensing Pathway of Vibrio qinghaiensis sp.-Q67. Biology 2021, 10, 638. [CrossRef] [PubMed]

13. Jin, H.; Wang, C.; Shi, J.; Chen, L. Evaluation on joint toxicity of chlorinated anilines and cadmium to Photobacterium phosphoreum and QSAR analysis. J. Hazard. Mater. 2014, 279, 156-162. [CrossRef]

14. Ma, X.Y.; Wang, X.C.; Liu, Y.J. Study of the variation of ecotoxicity at different stages of domestic wastewater treatment using Vibrio-qinghaiensis sp.-Q67. J. Hazard. Mater. 2011, 190, 100-105. [CrossRef] [PubMed]

15. Sharifian, S.; Homaei, A.; Hemmati, R.; Khajeh, K. Light emission miracle in the sea and preeminent applications of bioluminescence in recent new biotechnology. J. Photochem. Photobiol. B 2017, 172, 115-128. [CrossRef]

16. Deeva, A.A.; Zykova, E.A.; Nemtseva, E.V.; Kratasyuk, V.A. Functional divergence between evolutionary-related LuxG and Fre oxidoreductases of luminous bacteria. Proteins 2019, 87, 723-729. [CrossRef]

17. Hoepker, A.C.; Wang, A.; Le Marois, A.; Suhling, K.; Yan, Y.; Marriott, G. Genetically encoded sensors of protein hydrodynamics and molecular proximity. Proc. Natl. Acad. Sci. USA 2015, 112, E2569-E2574. [CrossRef]

18. Gong, L.; Wu, Y.; Jian, Q.J.; Yin, C.X.; Li, T.T.; Gupta, V.K.; Duan, X.W.; Jiang, Y.M. Complete genome sequencing of the luminescent bacterium, Vibrio qinghaiensis sp. Q67 using PacBio technology. Sci. Data 2018, 5, 170205. [CrossRef]

19. Tabib, C.R.; Brodl, E.; Macheroux, P. Evidence for the generation of myristylated FMN by bacterial luciferase. Mol. Microbiol. 2017, 104, 1027-1036. [CrossRef]

20. Tanet, L.; Tamburini, C.; Baumas, C.; Garel, M.; Simon, G.; Casalot, L. Bacterial Bioluminescence: Light Emission in Photobacterium phosphoreum Is Not under Quorum-Sensing Control. Front. Microbiol. 2019, 10, 365. [CrossRef]

21. Nealson, K.H.; Hastings, J.W. Bacterial bioluminescence: Its control and ecological significance. Microbiol. Rev. 1979, 43, 496-518. [CrossRef] [PubMed]

22. Dunlap, P. Biochemistry and genetics of bacterial bioluminescence. Adv. Biochem. Eng. Biotechnol. 2014, 144, 37-64. [CrossRef] [PubMed]

23. Bergner, T.; Tabib, C.R.; Winkler, A.; Stipsits, S.; Kayer, H.; Lee, J.; Malthouse, J.P.; Mayhew, S.; Muller, F.; Gruber, K.; et al. Structural and biochemical properties of LuxF from Photobacterium leiognathi. Biochim. Biophys. Acta 2015, 1854, $1466-1475$. [CrossRef] [PubMed]

24. Visick, K.G.; Ruby, E.G. Construction and symbiotic competence of a luxA-deletion mutant of Vibrio fischeri. Gene 1996, 175, 89-94. [CrossRef]

25. Xu, Y.; Wang, C.; Hou, J.; Wang, P.; You, G.; Miao, L. Mechanistic understanding of cerium oxide nanoparticle-mediated biofilm formation in Pseudomonas aeruginosa. Environ. Sci. Pollut. Res. Int. 2018, 25, 34765-34776. [CrossRef]

26. Lv, L.; Feng, C.; Li, W.; Zhang, G.; Wang, P.; Ren, Z. Exogenous N-acyl-homoserine lactones promote the degradation of refractory organics in oligotrophic anaerobic granular sludge. Sci. Total Environ. 2021, 761, 143289. [CrossRef]

27. Ren, T.T.; Yu, H.Q.; Li, X.Y. The quorum-sensing effect of aerobic granules on bacterial adhesion, biofilm formation, and sludge granulation. Appl. Microbiol. Biotechnol. 2010, 88, 789-797. [CrossRef]

28. Perez, P.D.; Hagen, S.J. Heterogeneous response to a quorum-sensing signal in the luminescence of individual Vibrio fischeri. PLoS ONE 2010, 5, e15473. [CrossRef]

29. Smith, G.P.; Salisbury, V.C. Investigation of the mechanism by which sublethal erythromycin inhibits bacterial cell-cell communication. In Abstracts of the Interscience Conference on Antimicrobial Agents and Chemotherapy, 1st ed.; American Society for Microbiology: Chicago, IL, USA, 2003; p. 92.

30. Schaefer, A.L.; Hanzelka, B.L.; Eberhard, A.; Greenberg, E.P. Quorum sensing in Vibrio fischeri: Probing autoinducer-LuxR interactions with autoinducer analogs. J. Bacteriol. 1996, 178, 2897-2901. [CrossRef]

31. Hawver, L.A.; Jung, S.A.; Ng, W.L. Specificity and complexity in bacterial quorum-sensing systems. FEMS Microbiol. Rev. 2016, 40, 738-752. [CrossRef]

32. Alav, I.; Sutton, J.M.; Rahman, K.M. Role of bacterial efflux pumps in biofilm formation. J. Antimicrob. Chemother. 2018, 73, 2003-2020. [CrossRef] [PubMed]

33. Jia, R.; Unsal, T.; Xu, D.K.; Lekbach, Y.; Gu, T.Y. Microbiologically influenced corrosion and current mitigation strategies: A state of the art review. Int. Biodeterior. Biodegrad. 2019, 137, 42-58. [CrossRef]

34. Shastry, R.P.; Rekha, P.D.; Rai, V.R. Biofilm inhibitory activity of metallo-protein AHL-lactonase from cell-free lysate of endophytic Enterobacter species isolated from Coscinium fenestratum Gaertn. Biocatal. Agric. Biotechnol. 2019, 18, 101009. [CrossRef]

35. Wang, J.; Liu, Q.; Dong, D.; Hu, H.; Wu, B.; Ren, H. AHLs-mediated quorum sensing threshold and its response towards initial adhesion of wastewater biofilms. Water Res. 2021, 194, 116925. [CrossRef]

36. Hashmi, M.Z.; Naveedullah; Shen, H.; Zhu, S.; Yu, C.; Shen, C. Growth, bioluminescence and shoal behavior hormetic responses to inorganic and/or organic chemicals: A review. Environ. Int. 2014, 64, 28-39. [CrossRef] [PubMed]

37. Shen, K.; Shen, C.; Lu, Y.; Tang, X.; Zhang, C.; Chen, X.; Shi, J.; Lin, Q.; Chen, Y. Hormesis response of marine and freshwater luminescent bacteria to metal exposure. Biol. Res. 2009, 42, 183-187. [CrossRef] [PubMed]

38. Sun, H.; Yao, Z.; Wang, D.; Wu, X.; Lin, Z.; Liu, Y. A deep insight into the toxic mechanism for sulfonamides based on bacterial cell-cell communication. Environ. Int. 2019, 129, 185-193. [CrossRef] [PubMed]

39. Mo, L.Y.; Liu, Y.A.; Zhu, J.; Qin, L.T.; Liang, Y.P.; Zeng, H.H. Benefits from hazards, benefits from nothing, and benefits from benefits: The combined effects of five quaternary ammonium compounds to Vibrio qinghaiensis Q67. Environ. Sci. Eur. 2020, 32, 35. [CrossRef] 
40. Wang, L.J.; Liu, S.S.; Yuan, J.; Liu, H.L. Remarkable hormesis induced by 1-ethyl-3-methyl imidazolium tetrafluoroborate on Vibrio qinghaiensis sp.-Q67. Chemosphere 2011, 84, 1440-1445. [CrossRef]

41. Deng, Z.; Lin, Z.; Zou, X.; Yao, Z.; Tian, D.; Wang, D.; Yin, D. Model of hormesis and its toxicity mechanism based on quorum sensing: A case study on the toxicity of sulfonamides to Photobacterium phosphoreum. Environ. Sci. Technol. 2012, 46, $7746-7754$. [CrossRef] 